\title{
VENOUS DISTENSIBILITY OF THE HAND DURING VALSALVA'S MANEUVRE
}

\author{
BY \\ W. E. WATSON* \\ From the Department of Neurology, Churchill Hospital, Oxford \\ Received June 14, 1961
}

The response of the veins of the hand to abrupt elevation of intrathoracic pressure by Valsalva's manœuvre was investigated in nineteen normal subjects.

\section{Methods AND EXPRession of Results}

Venous distensibility of the hand was measured by comparing the increase in hand volume resulting from intermittent obstruction of the venous return with the rise in venous pressure of the hand.

Hand volume changes were measured with a water-filled plethysmograph of $5 \cdot 16$ litres capacity. The water was continuously stirred and maintained at a temperature of $34 \pm 0 \cdot 5^{\circ} \mathrm{C}$. throughout each investigation. The water within the plethysmograph exerted a hydrostatic pressure of $8-11 \mathrm{~cm}$. water upon the back of the hand. The subject lay supine with the hand within the plethysmograph at the level of the manubrium sterni. Hand volume changes were derived from pressure changes of the air contained in the turret of the plethysmograph. Ambient temperature was within the range $22^{\circ}-25^{\circ} \mathrm{C}$., and constant throughout each investigation.

Hand venous pressure was measured through a nylon catheter of $0.8 \mathrm{~mm}$. internal diameter introduced percutaneously on the dorsal or radial aspect of the wrist joint and directed peripherally, negotiating at least one venous valve until the end of the catheter lay about $5 \mathrm{~cm}$. distal to the site at which the vein was punctured. Care was taken that the end of the catheter was not wedged in a venous tributary. The catheter was periodically flushed with $0.2 \mathrm{ml}$. of a solution containing $0.01 \mathrm{mg} . / \mathrm{ml}$. of heparin.

All pressures were measured with capacitance transducers (Southern Instruments) and records were obtained with a four channel direct writing pen unit. The pens were $16 \mathrm{~cm}$. long and worked in an arc of $4 \mathrm{~cm}$. The peak to peak response time of the pens was 0.07 seconds. The paper speed usually used was $5 \mathrm{~mm}$./sec.

An occluding pneumatic cuff was placed round the wrist immediately proximal to the plethysmograph, and intermittently inflated to $40 \mathrm{~mm}$. $\mathrm{Hg}$ for ten seconds.

The increase in hand volume was expressed graphically against the increase in venous pressure. The slope of the resulting line represented the venous distensibility. The measured increase in hand venous pressure included the transmitted rise in pressure within the plethysmograph as a consequence of increase in hand volume. The true rise in venous pressure was therefore derived by subtracting the rise in pressure within the plethysmograph from the total rise in venous pressure. The rise in pressure within the plethysmograph during an episode of venous tamponade never exceeded 7 per cent of the total rise in venous pressure, so this correction was a small one.

The transmural hand venous pressure or venous distending pressure was derived by subtracting

* Present adress: Royal Northern Hospital, Holloway Road, London. 


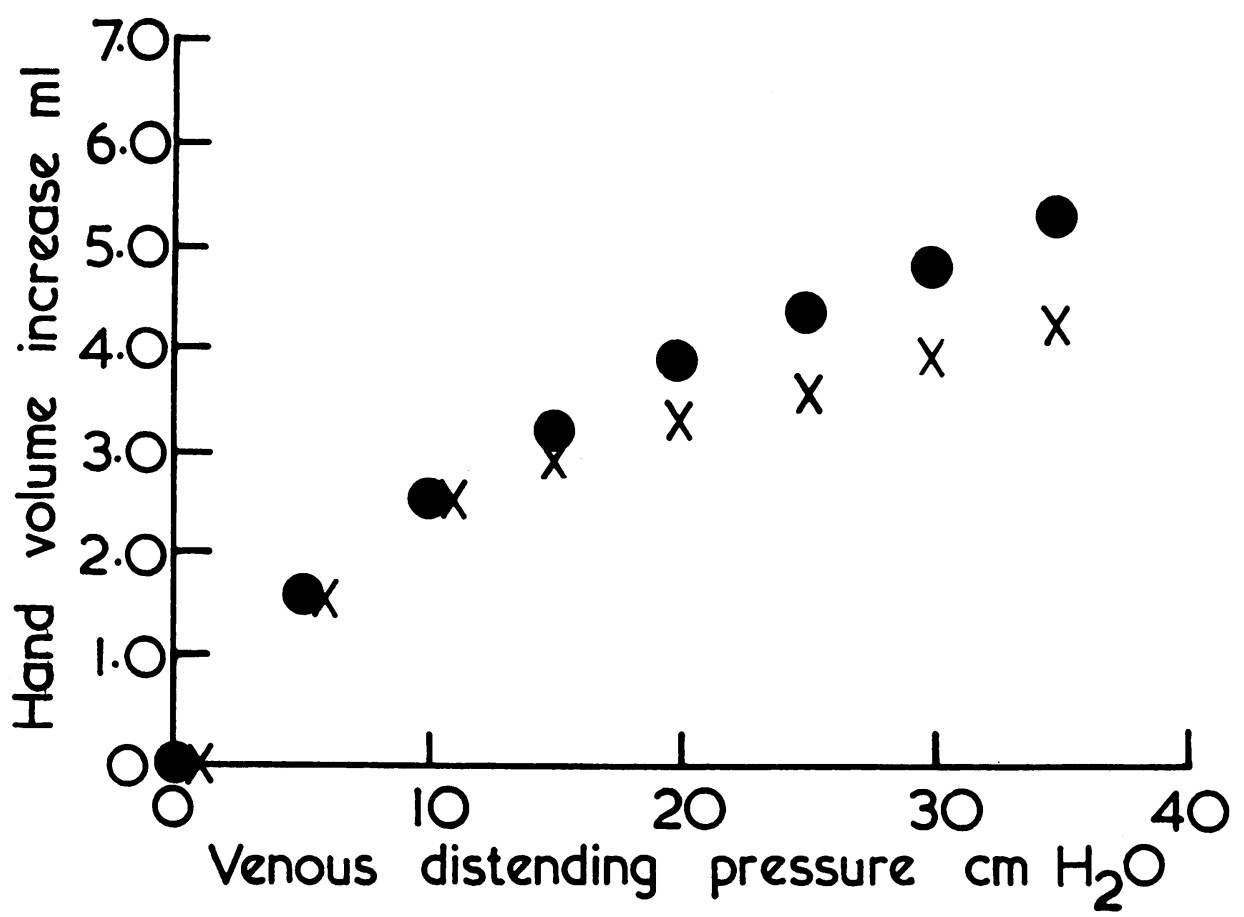

FIG. 1.-Vascular pressure-volume relationship of the hand.

- before Valsalva's manœuvre.

$\times$ during Valsalva's manœuvre.

the hydrostatic pressure due to the column of water within the plethysmograph above the back of the hand from the venous pressure. This hydrostatic pressure always exceeded the resting hand venous pressure. As the hydrostatic pressure was directly transmitted both to hand tissues and to hand veins the venous distending pressure was near zero between episodes of venous occlusion, indicating that the veins were collapsed (Ryder et al., 1944).

After the apparatus had been set up no measurement of capacity vessel distensibility was made for about 30 minutes. Twenty consecutive records were then analysed. The patient then performed Valsalva's manœuvre, straining maximally against a closed glottis for twenty seconds; during this time, and for the following ten minutes frequent estimations were made of the distensibility of the capacity vessels. This procedure was repeated two or three times in each subject.

Nineteen male subjects were investigated. Their ages were within the range 19-44 years. None had clinical evidence of disease of the respiratory or circulatory systems. All lay supine during investigations and were relaxed and comfortable. They were not permitted to sleep.

\section{RESULTS}

Fig. 1 shows a result obtained from one subject and is typical of all. The increase in hand volume is expressed graphically against the hand venous transmural pressure. The solid dots represent the mean of values obtained during twenty consecutive inflations immediately before the Valsalva manœuvre was performed. The crosses represent values obtained during the Valsalva manœuvre. In all subjects, during the Valsalva manœuvre the venous distensibility decreased. This decrease, which was apparently greatest at high venous pressures, was highly significant $(\mathrm{P}<0.01)$. As progressive rise in the peripheral venous pressure occurred during the Valsalva 


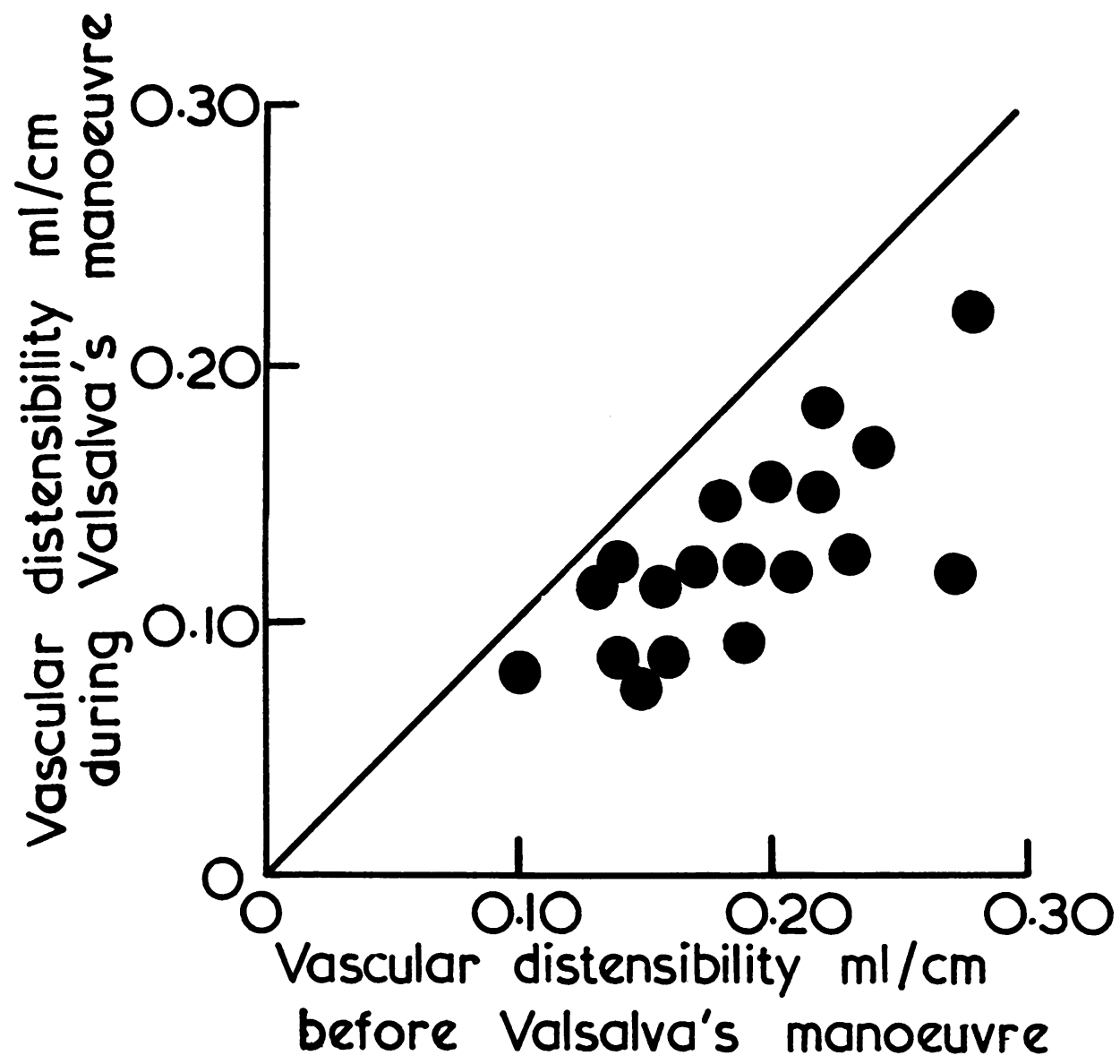

FIG. 2.-Vascular distensibility of the hand during Valsalva's manœuvre expressed graphically against values obtained before the manœuvre. In each subject, both values were measured at a constant hand volume.

manœuvre, changes which occurred late in the manœuvre affected the hand venous distensibility at high venous pressures only. The decrease in distensibility observed (Fig. 1) began 5 to 10 seconds after the beginning of the manœuvre.

The hand vascular pressure-volume relationship is curvilinear (Fig. 1) and venous distensibility is represented by the slope of this curve. If, under different circumstances, comparable values for venous distensibility are to be obtained it must be measured at a constant hand volume. The volume chosen in this investigation for each subject was the hand volume at the fifteenth second of the Valsalva manœuvre. Vascular distensibility was measured at this volume both in the periods of venous tamponade before the Valsalva manœuvre was performed and during the manœuvre. The results obtained in nineteen subjects are shown in Fig. 2. A reduction of hand venous distensibility occurred in all when the Valsalva manœuvre was performed.

Fig. 3 expresses venous distensibility measured at the constant hand volume described above against time, both before and at differing periods after the Valsalva manœuvre. In all subjects the venous distensibility remained low for 30 seconds after the end of the manœuvre, and in a few subjects it remained low for three minutes. 


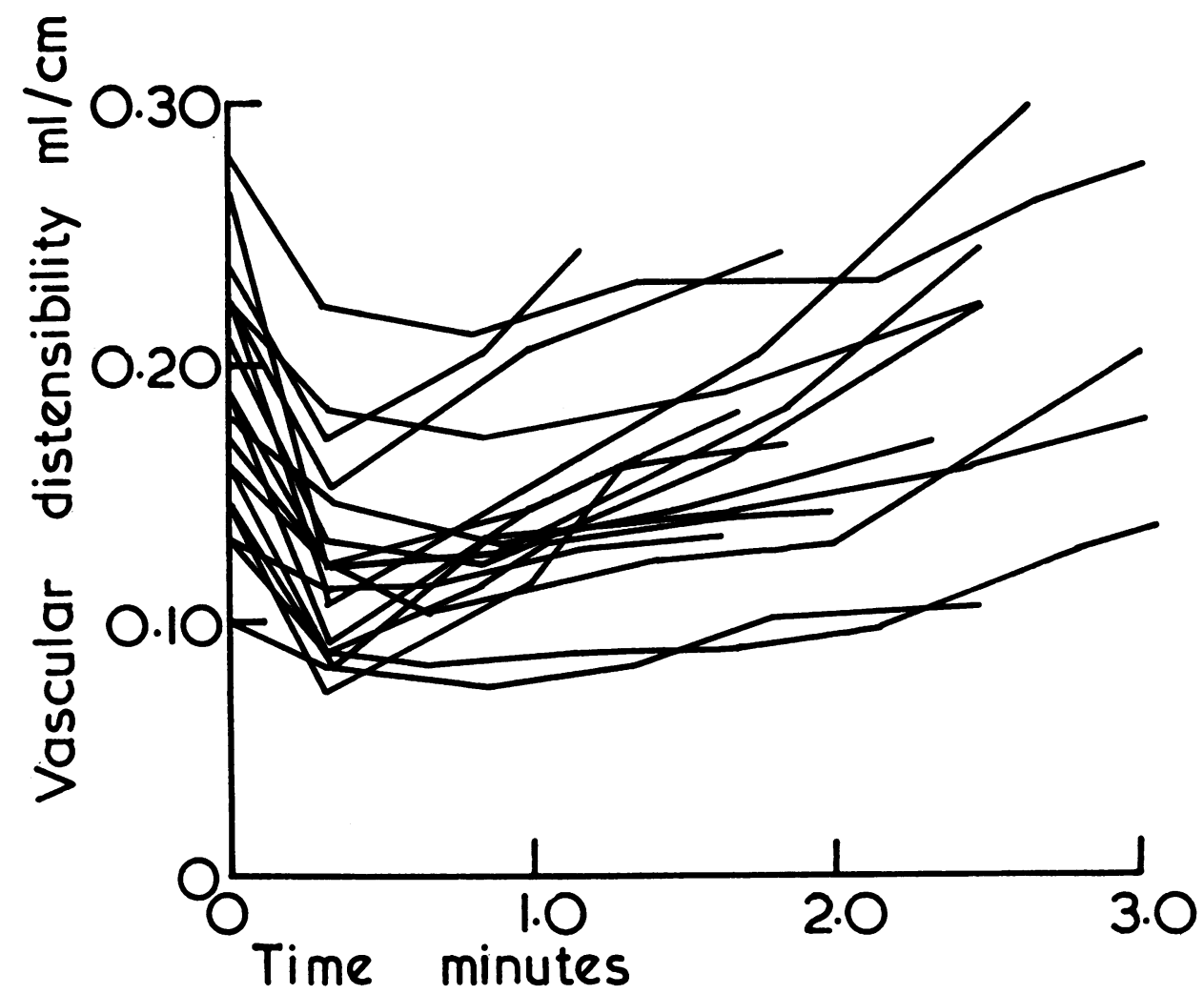

FIG. 3.-Vascular distensibility of the hand expressed graphically against time for nineteen subjects. In the first twenty seconds Valsalva's manœuvre occurs. Vascular distensibility returns to its initial value 30 seconds to 3 minutes after Valsalva's manœuvre is ended.

\section{Discussion}

The technique used in this investigation is similar to that employed by Sharpey Schafer (1961) to determine the vascular pressure-volume relationship of the forearm. It is related to the plethysmographic methods of determining venous distensibility in vivo (Clark, 1933; Kidd and Lyons, 1958; Glover et al., 1958; Eckstein and Horsley, 1960). The vessels investigated are the low pressure capacity vessels which consist almost entirely of veins (Litter and Wood, 1954). These vessels were collapsed by the imposed hydrostatic pressure of the fluid within the plethysmograph, so that a reasonably constant baseline hand volume was assured (Clark, 1933).

The abrupt elevation of mean intrathoracic pressure that occurs during Valsalva's manœuvre causes a marked fall in the filling pressure of the right side of the heart (Lee et al., 1954). Blood pressure changes and alterations of forearm blood flow in response to this have been extensively investigated (Sharpey Schafer, 1953, 1955).

The results presented in this paper show that the distensibility of the capacity vessels of the hand decreases when the Valsalva manouvre is performed by a normal subject. This decrease in distensibility begins about 10 seconds after the intrathoracic pressure is raised, and persists for a varying time after it has returned to normal. In most subjects vascular distensibility returns to its previous value within 30 seconds, but occasionally the capacity vessels remain less distensible for up to three minutes. 
If these observations made upon the hand represent changes occurring generally in the systemic muscular veins, the decreased overall distensibility of the systemic capacity vessels will reduce the volume of blood which is held back in the vascular dead space of the venous tree by the raised intrathoracic pressure. Persistence of the decreased venous distensibility after straining ceased would raise the filling pressure of the right side of the heart to a greater degree, and this is probably responsible in part for the "overshoot" of the arterial blood pressure.

\section{SUMMARY}

The distensibility of the low pressure capacity vessels of the hand was measured in normal subjects while they performed Valsalva's manœuvre.

A marked decrease in distensibility occurred about 10 seconds after the onset of Valsalva's manœuvre and persisted for a variable time after straining ceased.

It is suggested that the fall in distensibility of the systemic low pressure capacity vessels is in part responsible for the characteristic "overshoot" of the arterial blood pressure found when straining ceases.

This work was done in the Department of Neurology, Oxford, under the direction of Dr. W. Ritchie Russell who gave constant encouragement and supplied the apparatus. Dr. J. M. K. Spalding gave valuable advice and discussed the results on many occasions. Dr. A. C. Smith of the Nuffield Department of Anæsthetics gave expert practical assistance. Dr. E. Seelye suggested improvements in the presentation of the results.

\section{REFERENCES}

Clark, J. H. (1933). Amer. J. Physiol., 105, 418.

Eckstein, J. W., and Horsley, A. W. (1960). J. Lab. Clin. Med., 56, 847.

Glover, W. E., Greenfield, A. D. M., Kidd, B. S. L., and Whelan, R. F. (1958). J. Physiol., 140, 113.

Kidd, B. S. L., and Lyons, S. M. (1958). J. Physiol., 140, 122.

Lee, G. de J., Matthews, M. B., and Sharpey-Schafer, E. P. (1954). Brit. Heart J., $16,311$.

Litter, J., and Wood, J. E. (1954). J. Clin. Invest., 33, 298.

Ryder, H. W., Molle, W. E., and Ferris, E. B. (1944). J. Clin. Invest., 23, 333.

Sharpey-Schafer, E. P. (1953). J. Physiol., 122, 351.

- (1955). Brit. med. J., 1, 693.

- (1961). Oliver Sharpey Lectures, Royal College of Physicians. 